\title{
SURFACE POLYMERIZATION OF MONOMERS ON THE POLYETHYLENE TEREPHTHALATE MEMBRANE IN LOW TEM PERATURE PLASMA FOR WATER TREATMENT
}

\author{
Viacheslav Trachevskyi ${ }^{1,2}{ }^{*}$, Polina Vakuliuk ${ }^{3}, \mathrm{Nikolay}_{\text {Kartel }}{ }^{1,4}$, Wang $\mathrm{Bo}^{1}$
}

https://doi.org/10.23939/chcht12.01.064

\begin{abstract}
The plasma-chemical method of track-etched polyethylene terephthalate membranes surface modification by monomers with different chemical structure was developed. Physico-chemical properties of modified membranes were investigated. The authors showed the possibility of obtaining membranes with the required properties.
\end{abstract}

Keywords: polyethylene terephthalate membranes, plasma chemical modification, functional monomers, surface properties.

\section{Introduction}

Membrane filtration is one of the most prospective technological processes of complex mixtures separation. Track membranes (TM) play an important role among the materials used in this process [1]. Due to a number of properties, especially low thickness and high homogeneity of pores, TM have an insignificant resistance to the flow through the filtering medium, high selectivity of separation, low adsorption of solutes and ease regeneration. All this favorably distinguishes TM from other filtering materials and makes them widely used in medicine and biotechnology.

However, a surface of such membranes is hydrophilic and does not have bactericidal characteristics that limit their practical application substantially. Increase of surface hydrophilicity and giving it bactericidal properties extend the range of functional properties of this polymer.

A new trend has been developed in technology of track membranes in recent years - membrane surface modification, which refers to a deliberate change in the structure of a membrane surface layer, which leads to

\footnotetext{
${ }^{1}$ Ningbo University of Technology, 201 Fenghua Rd, Jiangbei Qu, Ningbo Shi, Zhejiang Sheng, China 315000

${ }^{2}$ National Aviation University, 1 Komarova Ave., 03058 Kyiv, Ukraine

${ }^{3}$ National University of "Kyiv-Mohyla Academy", 2 Skovorody St., 04070 Kyiv, Ukraine

${ }^{4}$ Chuiko Institute of Surface Chemistry, 17 Generala Naumova St.,

03164 Kyiv, Ukraine

meches49@ukr.net

(c) Trachevskyi V., Vakuliuk P., Kartel N., Bo W., 2018
}

obtaining the required properties. There are a lot of physical and chemical methods of modifying the surface properties of polymeric materials.

$\mathrm{TM}$ and the radiation-chemical inoculation of the so-called "clever" polymers are described in the research works on fundamental possibility of modification $[2,3]$. However, authors marked that practically all abovementioned works constrained with the use of radiationchemical methods of TM modification, that these methods cause the change of pores sizes. In addition it is marked in a number of works that even at the small degrees of inoculation $(2-4 \%)$ there is a substantial reduction of the modified membranes pores diameter because of filling foremost of mouths of pores by a modifying agent. Other approach to retrofitting the track membranes surface is the use of chemical inoculation or adsorption. In most researches sanctified to these methods, it is also marked, that their overuse brings substantial changes to a membranes morphology structure.

Different ways of surfaces chemical modification include the covalent joining of different functional groups or polymerization on the surface of track membranes pores which often result in out-of-control cladding of membrane filter pores.

The plasma-chemical method has the greatest advantage over the others [3-6]. Specific effect of low temperature plasma on different materials defined its widespread use in solving various technological problems in scientific research practice. This specificity is the combination of high chemical activity with low gas temperature, which makes plasma an effective tool in polymer modification. An additional advantage of plasma action is that it impacts only small depths, not exceeding a few micrometers, keeping the bulk properties of a material unchanged. Thus, plasma treatment actually converts the polymer into a new composite material.

The main advantage of the plasma-chemical method is the possibility to use it for modification of a wide range of chemical compounds (both organic and inorganic). Chemical reactions that take place in plasma discharge and determine the polymer surface modification are mainly defined by the composition of the plasma gas. 
When monomers of organic compounds are injected into plasma, the following processes are observed: monomer polymerization and deposition of polymer film onto the polymer surface. New surface properties largely depend on the type of chemical compound used as the plasma gas. The process of applying a thin polymer layer on the membrane surface in plasma is particularly interesting, as it allows obtaining a membrane with predetermined functional characteristics.

In addition, an important feature and significant advantage of plasma chemical modification is that a thin sub surface layer, which thickness varies from $10 \mathrm{~nm}$ to several microns, is subjected to changes. The bulk of the polymer thus does not change, preserving the mechanical, physico-chemical and electro-physical properties of the source material. The range of thicknesses of the modified layer for evaluation is very broad, but experimental data on the determination of the thickness of the modified layer in the literature is not given.

It can thus be concluded that polymerization initiated by plasma is a highly effective method of polymer and polymer membrane surface modification. This method allows for very precise and purposeful modification by plasma processing of polymers or plasmainitiated polymerization. It is worth noting that this method is applicable for almost any polymeric material.

The purpose of our study was:

- to study track membrane surface modification in low-temperature plasma;

- to develop a way of modifying PET membranes by plasma with monomers of different chemical nature to obtain membranes with predetermined functional characteristics.

It is known that one of the main obstacles to a prolonged use of membranes is their propensity to biological contamination and biodestruction. Formation and modification of membranes and preventing their contamination with a variety of microflora will greatly contribute to maintaining their productivity and lengthening the duration of their operation. It is quite promising in creating polymeric membranes with antibacterial properties is immobilization on the surface of the last iodine or copper atoms with a high bactericidal action against microorganisms. The disinfection properties of iodine or copper atoms are the ability to replace the covalently bonded hydrogen in $-\mathrm{OH},-\mathrm{NH}$, and $-\mathrm{SH}$ groups of molecules contained in the cell walls of the bacteria.

\section{Experimental}

The track microfiltration membranes of an isotropic structure of PET with pore diameters $D=500 \mathrm{~nm}$ (pore density $1.0 \cdot 10^{8} \mathrm{~cm}^{-2}$ ) with a thickness of $10 \mu \mathrm{m}$ were used.

To modify the surface of TM, methacrylic acid (MAC), vinylpyrrolidone (VPD), tetrafluoroethane (TFE) were used.
Grafting of monomers to the polyethylene terephthalate (PET) membrane surface was conducted in the developed plasma chemical installation using a highfrequency (HF) discharge of $13.56 \mathrm{MHz}$. The conditions of membrane surface plasma-chemical modification were experimentally chosen: pressure $13.32 \mathrm{~Pa}$, temperature $313-323 \mathrm{~K}$, monomer flow rate $8-10 \mathrm{~cm}^{3} / \mathrm{min}$, power 25-30 W (Fig. 1).

The efficiency of plasma chemical modification was estimated by measuring membrane surface contact angle, grafting degree of functional monomers, and volumetric water flow through the membrane by the standard methods [7].

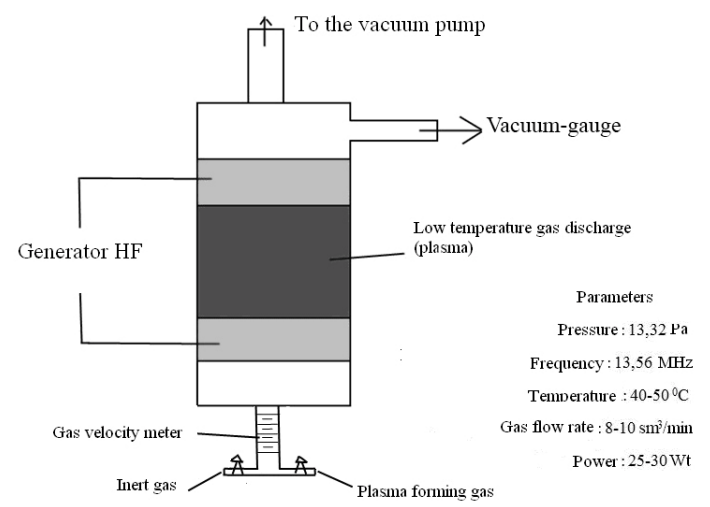

Fig. 1. Installation for plasma chemical membrane modification

\section{Results and Discussion}

Physico-chemical modification of hydrophobic membrane allows:

- to make the surface hydrophilic (including the surface of pores), which reduces their susceptibility to contamination (such as proteins, humic substances, etc.);

- to provide specific separation characteristics of membranes due to the formation of certain functional groups on membrane surface. Plasma-induced graft polymerization is one of the most effective and easy methods of membrane surface hydrophilization.

The following chemical reactions occur in oxygen plasma during membrane modification: the $\mathrm{C}-\mathrm{O}$ bond is broken, radicals are formed and then oxidized, and, as a result, a carboxyl group and a double bond are formed (Fig. 2).

During the plasma-chemical modification of membrane with methacrylic acid, radicals of acrylic acid and radicals on the membrane surface are formed, carbon chain is grafted and growing, and polymethyl methacrylate is formed (Fig. 3).

During the membrane surface modification with vinylpyrrolidone (Fig. 4) and tetrafluoroethane (Fig. 5) similar chemical reactions occur, by radical addition and formation of respective polymer on membrane surface. 


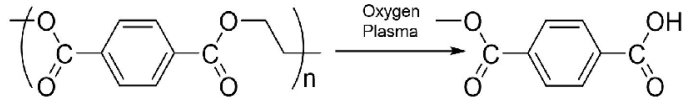

Fig. 2. Chemical transformations in oxygen plasma

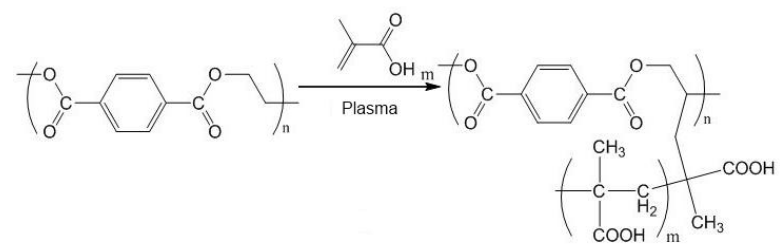

Fig. 3. Chemical changes in methacrylic acid plasma

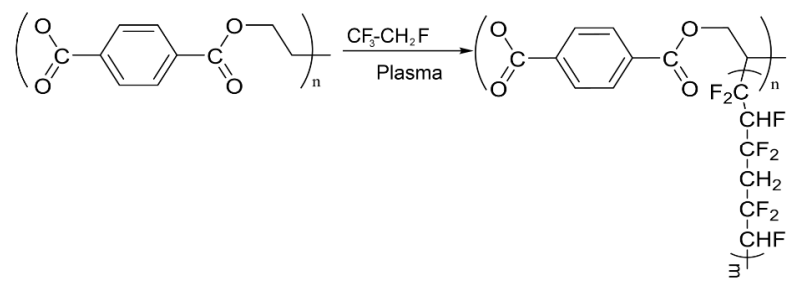

Fig. 4. Chemical changes in vinylpyrrolidone plasma

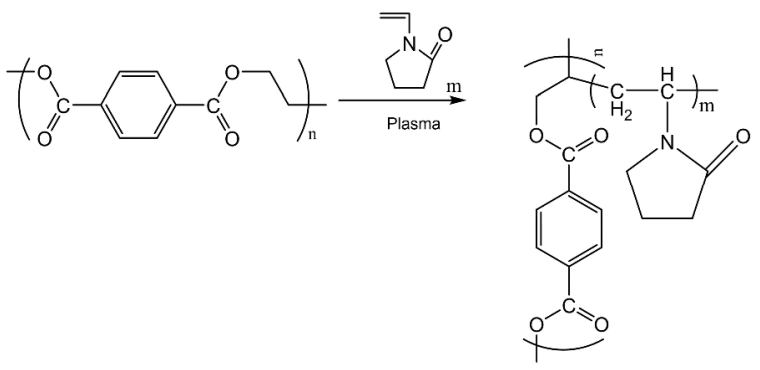

Fig. 5. Chemical changes in tetrafluoroethane plasma

The structural changes of membrane surface were studied by IR-spectroscopy. Spectrum of the membrane, modified in oxygen plasma, shows an increase of a peak at $1708.33 \mathrm{~cm}^{-1}$, which confirms that during modification the bonds are broken and carboxyl groups are formed.

Analysis of the IR-spectrum of the membrane surface, modified with polymethacrylic acid, indicates the intensity of stretching vibrations of the $\mathrm{C}=\mathrm{O}$ carboxyl group $\left(1706.42 \mathrm{~cm}^{-1}\right)$ compared to unmodified membrane. New absorption band also appears at $3423.10 \mathrm{~cm}^{-1}$, which corresponds to the stretching vibrations of $\mathrm{O}-\mathrm{H}$ bond; at $2964.17 \mathrm{~cm}^{-1}$, which corresponds to the asymmetric stretching vibrations of polymethacrylic acid $\mathrm{CH}_{3}$-group; and at $1178.44 \mathrm{~cm}^{-1}$, which corresponds to the stretching vibrations of $\mathrm{C}-\mathrm{O}$ bond.

Grafting of polymethacrylic acid is additionally confirmed by the increasing intensity of $\mathrm{O}-\mathrm{H}$ deformation vibration in a carboxyl group at frequency of $1408.41 \mathrm{~cm}^{-1}$. Analysis of the IR-spectrum of the membrane surface modified with vinylpyrrolidone revealed the appearance of a new absorption peak with a wavelength of $1655 \mathrm{~cm}^{-1}$, which corresponds to fluctuations of amide-carbonyl group in the $N$-vinyl-2-pyrrolidone ring. Furthermore, when increasing the degree of PVP grafting, the intensity of these peaks increased as well. Absorption at $1713 \mathrm{~cm}^{-1}$ is typical for aromatic compounds with $\mathrm{C}-\mathrm{H}$ and $\mathrm{C}=\mathrm{O}$ bonds. Also, there is an increase of peak intensity at $3394 \mathrm{~cm}^{-1}$ in the IR-spectrum. It also indicates that grafting is actually happening.

Research of the tetrafluoroethane-modified membrane surface structure by IR spectroscopy, shows the presence of several bands that are characteristic for polytetrafluoroethylene. These are bands with wavelengths of 1160 and $1220 \mathrm{~cm}^{-1}$, which correspond to symmetric and asymmetric $-\mathrm{CF}_{2}$ stretching vibrations of polytetrafluoroethylene; absorption bands at 513 and $555 \mathrm{~cm}^{-1}$ are associated with $-\mathrm{CF}_{2}$ circular and polygonal deformation vibrations; absorption bands in the 1400$1450 \mathrm{~cm}^{-1}$ region correspond to $\mathrm{C}-\mathrm{C}$ stretching vibrations in the main polymer chain and band with the wavelength of $990 \mathrm{~cm}^{-1}$ corresponds to $-\mathrm{CF}_{3}$ symmetric stretching vibrations. IR spectroscopy data confirm the fact that the polymer, which was synthesized by plasma discharge of 1,1,1,2-tetrafluoroethane, consists of $\mathrm{CF}_{2}$-groups.

While studying modification of track-etched membranes with monomers, it was found out that the increase of processing time leads to a sample mass growth due to the grafting of monomers to the membrane surface (Fig. 5). The opposite effect is observed while using oxygen as the acrogenous gas - the sample weight decreases due to the destruction and etching of the tracketched membrane surface.

The surface properties of PET membranes modified with oxygen, methacrylic acid and vinylpyrrolidone using the plasma chemical method were studied by water contact angle measuring. The results are shown in Table 1.

The extrapolation of data was shown using the graphs, which represent the dependence between the membrane surface contact angle and plasma processing time. Summary of membrane hydrophobicity is also given (Figs. 6-7).

The investigation of the process of track-etched membrane modifications has shown the hydrophobicity of all membranes increase, except the cases when using TFE (Fig. 8). This graph also represents that the optimal time for sample modification is $80 \mathrm{~s}$, because all significant changes in the values of contact angles occur up to $80 \mathrm{~s}$ and then almost no change takes place.

Protein adsorption on plasma-modified membrane surface in a variety of conditions was also studied.

Plasma graft polymerization leads to the decrease in the effective membrane pores radius, which causes a transmembrane volumetric water flow value to drop. Thus, the degree of grafting can be characterized by the change of volumetric water flow through the membrane before and after modification.

As shown in Fig. 9, there was a strong decrease of the volumetric water flow through the membranes, which were plasma-treated for 30 and $120 \mathrm{~s}$. This can be 
explained by a monomer grafting to the surface. In case of longer modification time, the gradual decrease of the volumetric water flow occurs. After $120 \mathrm{~s}$ of treatment, the decrease becomes less visible. This can be explained by the surface saturation with monomers. Considering the results above, the optimal duration of modification is $120 \mathrm{~s}$.

Antimicrobial properties of track membranes.

To create antimicrobial TM, it was tested on Staphylococcus aureus bacteria detoxification. For that case, the bacterial suspension was passed through TM. And the number of colony-forming units was calculated in the filtrate.

One of the methods of bactericidal substances immobilization on the membranes surface is the creation of appropriate reactive groups, which create the polymerized polymer complexes by bactericidal polymers, resulting in the linking of a selective layer of the antibacterial polymer. The grafted ionogenic polymer not only provides the membrane with hydrophilic properties, but can also be used to give the membrane antimicrobial properties, as a result of immobilization on its surface of metals that possess a bactericidal action, for example, copper.
Mobilization of copper on modified TM was carried out by the silver ions sorption on MAC carboxyl groups. Afterwards, the subsequent restoration of sorbed copper and the formation of initial nanoclusters, and then metal copper nanoparticles took place.

Modification of TM from grafted MAC of copper was carried out from an aqueous solution of midi chloride followed by the membrane drying at room temperature and short-term heating at $413 \mathrm{~K}$ for the recovery of $\mathrm{Cu}^{2+}$ to $\mathrm{Cu}^{0}$. As a result of this treatment, nanoclusters are first formed, and then copper nanoparticles are formed due to the presence of MAC macromolecules on the surface of the membrane, which obstruct the aggregation of copper atoms that are formed during the process of $\mathrm{Cu}^{2}+$ recovery.

The amount of copper nanoparticles immobilized on TM, depending on the degree of vaccination of MAC is presented in Fig. 10.

As can be seen from Fig. 10, with increasing content on the surface of the modified TM, the carboxyl groups of the MAC increase the copper concentration on the surface of the modified membrane.

Table 1

The membrane surface contact angles

\begin{tabular}{|l|c|c|c|c|}
\hline \multirow{2}{*}{ Plasma gas } & \multicolumn{4}{c|}{ Time, s } \\
\cline { 2 - 5 } & 30 & 120 & 210 & 300 \\
\hline Oxygen & 28 & 23 & 23 & 23 \\
\hline Methacrylic acid & 57 & 49 & 45 & 45 \\
\hline Vinylpyrrolidone & 47 & 39 & 34 & 34 \\
\hline
\end{tabular}

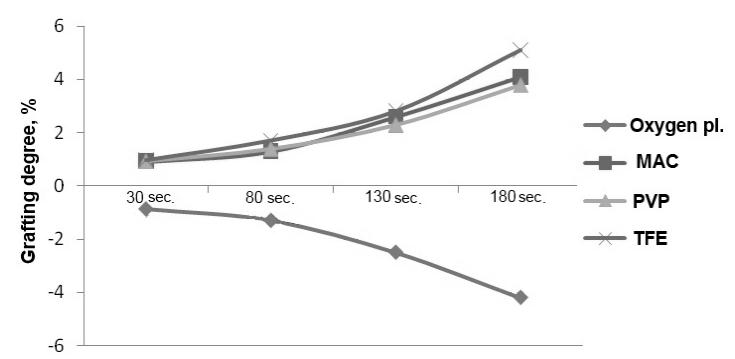

Fig. 6. Dependence between the grafting degree and the time

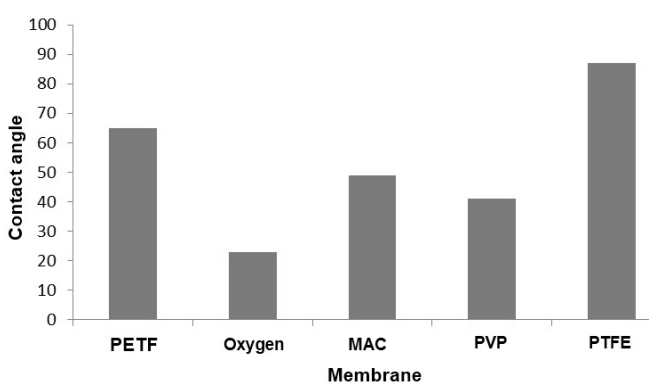

Fig. 8. The contact angles obtained at the optimal time of modification by low-temperature plasma

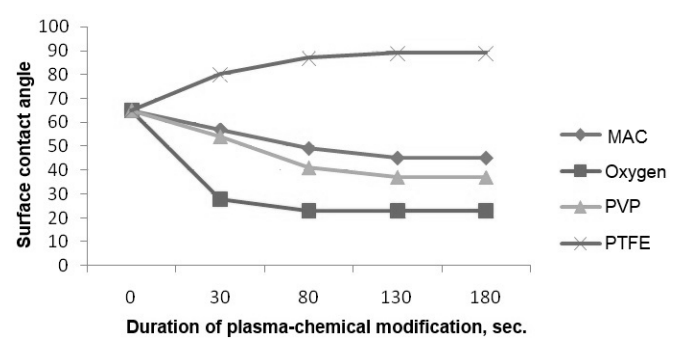

Fig. 7. Dependence between the surface contact angle and plasma processing time of the track-etched membranes

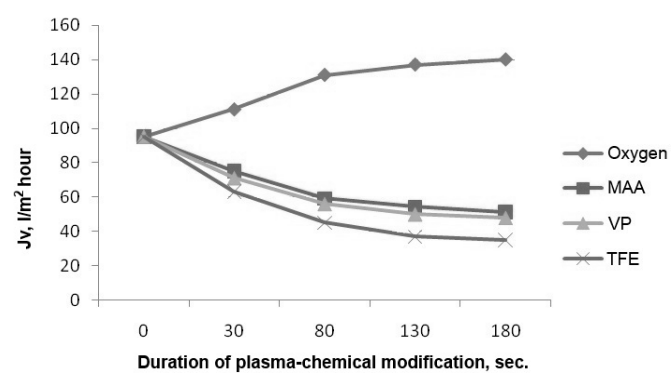

Fig. 9. Dependence of the volumetric water flow through the membrane on the duration of plasma-chemical modification 
Bactericidal activity of modified membranes

\begin{tabular}{|c|c|c|c|c|}
\hline \multirow{2}{*}{ Time, s } & \multicolumn{3}{|c|}{ Growth of bacteria } & \multirow{2}{*}{ Bactericidal acitivity, \% } \\
\cline { 2 - 5 } & Escherichia coli BE & Bactericidal activity & Escherichia coli & 0 \\
\hline 0 & ++++ & ++++ & +++ & 99 \\
\hline 30 & + & - & + & 99.9 \\
\hline 60 & + & - & - & 99.9 \\
\hline 120 & + & - & + & 95 \\
\hline & & Staphylococcus aurous & 98 \\
\hline 30 & ++ & + & + & 98 \\
\hline
\end{tabular}

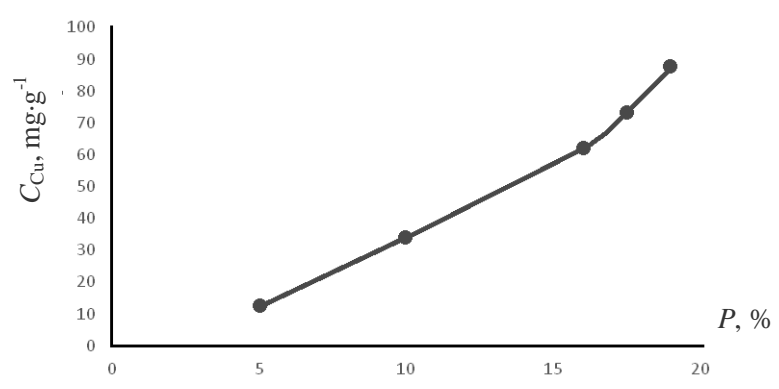

Fig. 10. Dependence of the copper nanoparticles concentration $C_{\mathrm{Cu}}\left(\mathrm{mg}_{\mathrm{g}} \mathrm{g}^{-1}\right)$ immobilized on modified TM, on the degree of inoculation on the of the membrane MAC surface $(P, \%)$

The antibacterial activity of the modified membranes against gram-negative bacterium Escherichia coli and the gram-negative bacterium Staphylococcus aurous is found to be dependent on the amount of grafted monomer, which is equivalent to the concentration of immobilization copper, determined by the processing time in the low-temperature gas discharges MAC (Table 2).

As can be seen from Table 1, for all nanomodified membranes the bactericidal activity against gram-negative bacteria is higher than with respect to gram-positive ones. The antibacterial activity of the specimens practically does not increase for modified membranes depending on the time of plasma processing.

So, at the modification time of $30 \mathrm{~s}$ the membranes are characterized as $99.9 \%$ bactericidal ones. In addition, they do not lose their antibacterial properties after immobilization on the membranes surface, which makes it possible to widely apply them in this direction.

\section{Conclusions}

In this study, the plasma chemical methods of the PET track-etched membrane surface modification were developed with the purpose of changing their hydrophilic/hydrophobic characteristics. Optimal modification parameters were used to obtain the membranes with predetermined functional properties of their surface (pressure 13.32 $\mathrm{Pa}$, frequency $13.56 \mathrm{MHz}$, temperature $313-323 \mathrm{~K}$, power $25-30 \mathrm{~W}$, gas flow rate $8-10 \mathrm{~cm}^{3} / \mathrm{min}$ ).
The presence of characteristic absorption bands for modifiers was proven by infrared spectroscopy $(\mathrm{C}=\mathrm{O}$ $1706.42 \mathrm{~cm}^{-1} ;-\mathrm{CF}_{2} 1160$ and $1220 \mathrm{~cm}^{-1}$ ). The possibility of plasma chemical surface modification of PET track-etched membranes with the purpose to obtain the required properties was shown. It has been established that plasma chemical modification with subsequent immobilization of copper nanoparticles on the membranes surface allows to obtain membranes with high antibacterial activity. In addition, they do not lose their antibacterial properties in time.

\section{References}

[1] Mulder M.: Basic Principles of Membrane Technology. Springer, Netherlands 1996. https://doi.org/10.1007/978-94-009-1766-8 [2] Titov V., Rybkin V., Smirnov S.: Khimiya Vysokykh Energiy, 2009, 43, 218.

[3] Tabatabaei S., Carreau P., Ajji A.: J. Membrane Sci., 2009, 345, 148. https://doi.org/10.1016/j.memsci.2009.08.038

[4] Kudashev S., Urmantsev U.: Physico-Khimiya Poverhnosti i

Zashchita Materialov, 2015, 51, 73.

[5] http://www.isuct.ru/eng/nich/konfer/plasma/LECTIONS/ Gilman_lection.html, free.

[6] Iwa T., Kumarawa H., Bae S.-Y.: J. Appl. Polym. Sci., 2004, 94, 758. https://doi.org/10.1002/app.20961

[7] Shcherbina A., Chalykh A.: Physico-Khimiya Poverhnosti i

Zashchita Materialov, 2015, 51, 231.

Received: December 20, 2016 / Revised: September 03, 2017 / Accepted: December 02, 2017

\section{ПОВЕРХНЕВА ПОЛІМЕРИЗАЦІЯ МОНОМЕРІВ НА ПОЛІЕТИЛЕНТЕРЕФТАЛАТНІЙ МЕМБРАНІ В НИЗЬКОТЕМПЕРАТУРНІЙ ПЛАЗМІ ДЛЯ ОЧИЩЕННЯ ВОДИ}

Анотація. Розроблена плазмохімічна методика модифікаиії поверхні полиетилентерефталатних мембран мономерами різної хімічної структури. Досліджені фізико-хімічні властивості модифікованих мембран. Показана можливість отримання мембран з необхіднии властивостями.

Ключові слова: поліетилентерефталатні мембрани, плазмохімічна модифікація, функціональні мономери, властивості поверхні. 